\title{
Prediction of seam performance of light weight woven fabrics
}

\author{
Khaled M. Elsheikh, M. Shawky, H.M. Darwish, E.A. Elsamea
}

\begin{abstract}
Light weight fabrics are selected for their aesthetic qualities, drape, and handle. But these fabrics are difficult to sew. Seams are the basic elements in a structure of any apparel. Seam performance affects the quality of the apparel product. In this research seam performance of two kinds of light woven fabrics differs in their construction (chiffon and satin) were studied in terms of seam strength, efficiency, and seam strain. The effect of some sewing parameters (sewing thread count, stitch density, needle size, stitch type) on seam strength, efficiency, and seam strain were investigated. Regression equations which can predict each of the previous parameters were concluded in both warp and weft directions. It was found that the stitch density and the interaction between thread count and stitch type affect warp seam strength for both chiffon and satin fabric. Sewing thread count has significant effect on seam stress in both directions for both fabrics under study. Also it affects seam strain in warp direction for satin fabric. The significant effect of sewing needle count on seam performance appears only in seam stress in warp direction for chiffon fabric.
\end{abstract}

Index Terms - Seam stress, Seam efficiency, Seam strain, Fabric strength, sewing thread.

\section{INTRODUCTION}

The quality of the seam can be analyzed in two essential criteria: the functional and aesthetic performance criteria that are needed for the garment through the final use. The functional performance is primarily indicating the strength and the efficiency of the seam. For better seam quality, it is important to consider the complete harmony of the key fabric properties, sewing thread properties, and sewing condition parameters used [1]. The higher the stitch density the higher the seam breaking load and displacement in warp direction. The stitch density has an effect on the difference between seam breaking load before and after laundry in weft direction. Also it interacts with sewing thread type. The higher the stitch density the lower the differences between seam breaking load before and after laundry [2]. It was found that it is preferable to use fine polyester or coarser cotton sewing thread with light weight denim fabrics [3].

Stitch density affects seam strength where seam strength values increased with high stitch densities [4, 5, and 6]. The effect of sewing thread, sewing needle count and material, and stitches per centimeter on seam strength for a plain woven cotton/ polyester fabric was investigated. The effect of sewing thread appears in some cases while the effect of sewing needle count appears in few cases ( increasing needle

Khaled M. Elsheikh, Apparel Design Management and Technology Department, Faculty of Applied Arts, Cairo, Egypt)

M. Shawky, Clothing and knitting Industrial Research Department, Textile Research Division, National Research Centre, Cairo, Egypt).

H.M. Darwish, Clothing and knitting Industrial Research Department, Textile Research Division, National Research Centre, Cairo, Egypt).

E.A. Elsamea. Clothing and knitting Industrial Research Department, Textile Research Division, National Research Centre, Cairo, Egypt). count decreased seam resistance), while the effect of the interaction between sewing thread and stitches per centimeter appears in most cases. When stitch density increased seam strength increased to a certain limit of stitch density after which a fabric mechanical damage produced by stitch needle action [7]. Different blend ratios was studied by using different compositions of polyester and cotton components ( $100 \%$ cotton, $15 \%$ polyester/ $85 \%$ cotton, $35 \%$ polyester/ $65 \%$ cotton), three different linear densities (40, 60, and 80 tex) of polyester/cotton core spun sewing thread and three needle sizes $(11,14$, and 16) were used to conclude their effect on seam strength and efficiency. It was found that Seam efficiency for higher percentage polyester fabrics was low and it increased in higher percentage cotton fabrics due to high extensibility of the used fabrics which based on polyester, seam efficiency increased with the sewing thread linear density because of the fact that more number of fibers is combined with the coarser sewing thread leads to high seam strength for higher percentage polyester fabrics [8]. Also the seam performance of 12 cotton and polyester woven fabrics with two different structures (plain and 3/1 twill) was investigated. These fabrics had three picks densities for every weave type. It was found that for cotton fabrics; seam strength values in weft direction increased with increasing in picks per inch for both plain and 3/1 twill weaves. Sewing thread count affects seam strength significantly [9]. The effect of sewing parameters on seam strength for denim fabrics was determined and equations that can be used to predict weft and warp seam strength were concluded. Four different denim fabrics produced with $100 \%$ cotton yarn with different warp and weft linear densities and different warp and weft densities so four fabric samples with different fabric constructions were attained. The sewing thread parameters were; 3 different raw materials (polyester/ cotton core spun, polyester/polyester core spun, and staple polyester), 3 different counts of polyester/cotton sewing threads (40, 60,120 Tex), and two different stitch densities $(3,5$ stitches $/ \mathrm{cm})$. It was found that the thicker thread increased the weft and warp seam strengths; warp seam strength was higher than weft seam strength with polyester /cotton core-spun sewing threads at 60 and 120 tex, The highest seam strength values were obtained with polyester/polyester core - spun and the most suitable sewing thread was polyester/cotton 120 tex with 260 and $400 \mathrm{~g} / \mathrm{m}^{2}$ [5]. The effect of sewing thread count and stitch density were studied on three types of sheer fabrics; chiffon, voile, and organza up to $50 \mathrm{~g} / \mathrm{m}^{2}$ with plain weave structure. Three sewing thread count $(28,31,33$ tex) of $100 \%$ polyester and three different stitch densities (7, 10, 13 stitch per inch) were used with 301 stitch type, needle number 11 and seam type ssa-1. It was concluded that different sheer fabric types gave different values with sewing thread performance based on the compactness of the fabric. For chiffon; the suitability of thread size was 33 tex by using $13 \mathrm{spi}$, for voile fabric; thread 
size of 31 tex was suitable to be used and sewing with 7 and 10 spi. For organza fabric; the sewing thread of 31 tex was suitable by using 7 spi [10]. For sewing machine setting there was a survey that was made among experts. It aimed to arrange ten factors influencing the seam's quality by sewing fine fabrics. On this basis three factors were chosen: straining of the upper thread (x1), needle size (x2), load of the pressing foot (x3). The research was carried out using stitch type 301, fabric super silk from $100 \%$ PES with mass per unit area 102 $\mathrm{g} / \mathrm{m} 2$, sewing thread from $100 \%$ PE number 180 . Three levels were selected for each parameter which where, straining of the upper thread, $\mathrm{x} 1(20,40,60) \mathrm{cN}$, needle size, $\mathrm{x} 2(60,70$, $80)$, load of the pressing foot $x 3(10,25,40) \mathrm{N}$. It was found that the optimal values of these factors, which leaded to the best seam strength, elongation and appearance were: straining of the upper thread (x1) between 35 and $40 \mathrm{cN}$; needle size (x2) 80; load of the pressing foot (x3) $40 \mathrm{~N}$ [11].

\section{MATERIALS AND METHODS}

Fabric specification and properties:

Two kinds of lightweight woven fabrics were chosen with different characteristics. Table I shows the description of fabrics specifications.

Table I: Fabric specification

\begin{tabular}{|c|c|c|c|c|c|c|c|}
\hline Fabric & Fabric & Weave & $\begin{array}{c}\text { Weight } \\
{\left[\mathbf{g} / \mathbf{m}^{2}\right]}\end{array}$ & \multicolumn{2}{|c|}{$\begin{array}{c}\text { Yarn linear } \\
\text { density } \\
\text { code }\end{array}$} & Content & \multicolumn{2}{|c|}{ Fabric density } \\
\cline { 5 - 8 } & structure & & Warp & Weft & $\begin{array}{c}\text { Ends } \\
\text { per } \\
\text { inch }\end{array}$ & $\begin{array}{c}\text { Picks } \\
\text { per } \\
\text { inch }\end{array}$ \\
\hline $\begin{array}{c}\text { Fabric1 } \\
\text { Chiffon }\end{array}$ & $\begin{array}{c}100 \% \\
\text { Polyester }\end{array}$ & Plain (1/1) & 79.2 & 75 & 75 & 97 & 69 \\
\hline $\begin{array}{c}\text { Fabric2 } \\
\text { Satin }\end{array}$ & $\begin{array}{c}100 \% \\
\text { Polyester }\end{array}$ & $\begin{array}{c}\text { Satin } \\
\text { (Atlas 5) }\end{array}$ & 97.9 & 50 & 75 & 254 & 94 \\
\hline
\end{tabular}

Table II: D.O.E for seam strength for fabric 1(chiffon)

\begin{tabular}{|c|c|c|c|c|}
\hline $\begin{array}{c}\text { Experiment. } \\
\text { No. }\end{array}$ & $\begin{array}{c}\text { Sewing } \\
\text { thread } \\
\text { count (tex) }\end{array}$ & $\begin{array}{c}\text { Stitches } \\
\text { per } \\
\text { centimeter }\end{array}$ & $\begin{array}{c}\text { Needle } \\
\text { size (Nm) }\end{array}$ & Stitch \\
type \\
\hline 1 & 24 & 5 & 70 & 301 \\
\hline 2 & 24 & 6 & 75 & 504 \\
\hline 3 & 24 & 7 & 80 & 515 \\
\hline 4 & 27 & 5 & 70 & 504 \\
\hline 5 & 27 & 6 & 75 & 515 \\
\hline 6 & 27 & 7 & 80 & 301 \\
\hline 7 & 24 & 5 & 75 & 301 \\
\hline 8 & 24 & 6 & 80 & 504 \\
\hline 9 & 24 & 7 & 70 & 515 \\
\hline
\end{tabular}

Table III: D.O.E for seam strength for fabric 2 (satin)

\begin{tabular}{|c|c|c|c|c|}
\hline $\begin{array}{c}\text { Experiment. } \\
\text { No. }\end{array}$ & $\begin{array}{c}\text { Sewing } \\
\text { thread } \\
\text { count } \\
\text { (Tex) }\end{array}$ & $\begin{array}{c}\text { Stitches } \\
\text { per } \\
\text { centimeter }\end{array}$ & $\begin{array}{c}\text { Needle } \\
\text { size (Nm) }\end{array}$ & $\begin{array}{c}\text { Stitch } \\
\text { type }\end{array}$ \\
\hline 10 & 27 & 5 & 80 & 515 \\
\hline 11 & 27 & 6 & 70 & 301 \\
\hline 12 & 27 & 7 & 75 & 504 \\
\hline 13 & 24 & 5 & 75 & 515 \\
\hline 14 & 24 & 6 & 80 & 301 \\
\hline 15 & 24 & 7 & 70 & 504 \\
\hline 16 & 24 & 5 & 80 & 504 \\
\hline 17 & 24 & 6 & 70 & 515 \\
\hline 18 & 24 & 7 & 75 & 301 \\
\hline
\end{tabular}

\section{Experimental procedures}

The experimental work was done by Tagoushi T18 experimental design, three factors at three levels $\left(3^{3}\right)$, and one factor at two levels $\left(1^{2}\right)$ with different sewing parameters for warp and weft directions. Tables II, III illustrates the design of experiments (D.O.E) for seam strength for both fabrics under study. Two sewing thread counts were used (24 and 27 Tex), three stitches per centimeter $(5,6,7$ stitches per centimeter), three needle sizes $(70,75,80)$, and three stitch types (301 lock stitch, 504 overlock with three threads, 515 overlock with 5 threads) were used.

\section{Fabric and seam strength test}

Fabric strength and elongation test was carried according to ASTM: D 5035[12].While seam strength and elongation test was done in both warp and weft directions for all experiments according to ISO: 13935-1[13]. Fabric and seam strength was tested using the Instron tensile tester 3345. Applying seam strength in warp direction means that stitch line follows weft thread yarns and vice versa.

\section{RESULTS AND DisCUSSION}

The interaction between different sewing parameters for two fabrics was investigated in relation with seam stress, seam strain, and seam efficiency. Seam stress expresses seam strength per unit area, while seam strain expresses seam elongation per unit length.

The stress and strain at auto break and maximum load were measured for the two fabrics under study and for seam lines of the eighteen experiments. Table IV shows fabric stress and strain at auto break and maximum load for both fabrics under study in both directions.

Table IV: fabric stress and strain for fabric 1, 2

\begin{tabular}{|c|c|c|c|c|c|c|c|}
\hline \multirow[t]{2}{*}{$\begin{array}{c}\text { Fabric } \\
\text { code }\end{array}$} & \multirow[t]{2}{*}{$\begin{array}{l}\text { Fabric } \\
\text { Content }\end{array}$} & \multirow[t]{2}{*}{$\begin{array}{c}\text { Weave } \\
\text { structure }\end{array}$} & \multirow[t]{2}{*}{$\begin{array}{r}\text { Weight } \\
{\left[\mathrm{g} / \mathrm{m}^{2}\right]}\end{array}$} & \multicolumn{2}{|c|}{$\begin{array}{c}\text { Yarn linear } \\
\text { density } \\
\text { (denier) }\end{array}$} & \multicolumn{2}{|c|}{$\begin{array}{l}\text { Fabric } \\
\text { density }\end{array}$} \\
\hline & & & & Warp & Weft & $\begin{array}{c}\text { Ends } \\
\text { per } \\
\text { inch } \\
\end{array}$ & $\begin{array}{c}\text { Picks } \\
\text { per } \\
\text { inch } \\
\end{array}$ \\
\hline $\begin{array}{l}\text { Fabric1 } \\
\text { Chiffon }\end{array}$ & $\begin{array}{c}100 \% \\
\text { Polyester }\end{array}$ & $\begin{array}{l}\text { Plain } \\
(1 / 1)\end{array}$ & 79.2 & 75 & 75 & 97 & 69 \\
\hline $\begin{array}{c}\text { Fabric2 } \\
\text { Satin }\end{array}$ & $\begin{array}{c}100 \% \\
\text { Polyester }\end{array}$ & $\begin{array}{c}\text { Satin } \\
\text { (Atlas 5) }\end{array}$ & 97.9 & 50 & 75 & 254 & 94 \\
\hline
\end{tabular}

The tenacity and strain at auto break and maximum load were measured for the two sewing threads under study. Table V shows the values of the tenacity and strain for both sewing threads that used in this study.

Table V: Tenacity and strain for two sewing thread counts

\begin{tabular}{|c|c|c|c|c|c|c|}
\hline $\begin{array}{c}\text { Thread } \\
\text { count }\end{array}$ & $\begin{array}{c}\text { Max } \\
\text { load. } \\
(\mathbf{K N})\end{array}$ & $\begin{array}{c}\text { Max } \\
\text { tenacity. } \\
(\mathbf{N} / \text { tex })\end{array}$ & $\begin{array}{c}\text { Max } \\
\text { strain. } \\
(\%)\end{array}$ & $\begin{array}{c}\text { Tenacity } \\
\text { at break } \\
(\mathbf{N} / \text { tex })\end{array}$ & $\begin{array}{c}\text { Strain } \\
\text { at } \\
\text { break } \\
(\%)\end{array}$ & $\begin{array}{c}\text { Load at } \\
\text { break } \\
(\mathbf{K N})\end{array}$ \\
\hline 27 & 0.00825 & 0.298 & 12.37 & 0.298 & 12.37 & 0.00825 \\
\hline 24 & 0.013 & 0.541 & 16.85 & 0.541 & 16.85 & 0.013 \\
\hline
\end{tabular}

Seam stress in warp direction for fabric 1 (chiffon) $Y=0.72+0.03 *$ st. $d^{2}-0.03 * n^{2}-0.07 *$ th s st.t $\quad R^{2}=0.9$

Where Y: seam stress in warp direction for fabric 1 (chiffon). St.d: stitch density.

n: sewing needle size in $\mathrm{Nm}$.

th: sewing thread count in Tex. 
st.t: stitch type.

From equation 1, it is obvious that square of needle size affects seam stress in warp direction negatively.The higher the needle size (coarser needle) the less the seam stress.

This is because the coarser the needle the bigger the pores it causes in the fabric which weaken the fabric and lead to its mechanical damage. Also the interaction between sewing thread count and stitch type also affect the seam stress negatively which means that the higher the yarn count in Tex (coarser yarn) gives lower seam stress in warp direction for chiffon fabric. (Contradicts with [5]). Also using of stitch type 515 (overlock with 5 thread) gives the lowest seam stress then comes stitch type 504 (overlock with 3 thread) then comes stitch type 301 (lockstitch). Also the stitch density has a positive effect on seam stress which means the more the stitches per centimeter the higher the seam stress because with increasing stitches per centimeter the contact surface between sewing thread and fabric yarn increases. From the previous speech it can be concluded that using stitch type 301 with yarn count 24 Tex and highest number of stitch density (7 stitches per $\mathrm{cm}$.), and lowest needle size (70) gives the higher seam strength in warp direction for chiffon fabric.

\section{Seam efficiency in warp direction for fabric 1 (chiffon) $Y=0.87+0.04 * s t . d^{2}-0.04 * n^{2}-0.09 *$ th $*$ st.t $\quad R^{2}=0.9$}

Where Y: seam efficiency in warp direction for fabric 1 (chiffon)

From equation 2 it is obvious that the factors affecting seam efficiency in warp direction for fabric1 (chiffon fabrics) are the same factors affecting seam stress in warp direction.

No relation could be obtained for neither seam stress for chiffon fabric in weft direction accordingly nor seam efficiency in weft direction.

Seam stress in warp direction for fabric 2 (satin) $Y=0.67-0.07 *$ th $* s t . t+0.02 * s t . d^{2} \quad R^{2}=0.81$

Where Y: seam stress in warp direction for fabric 2 (satin) It is clear that the interaction between sewing thread count and stitch type has a negative effect on seam stress in warp direction for satin fabric. This means that using thinnest sewing thread (24 Tex) with stitch type 301 (lock stitch) gives the highest seam stress. Also using the thickest sewing thread with stitch type 514 gives the lowest warp seam stress. On the other side the square of stitch density affects seam stress in warp direction positively, which means the more stitches per centimeter the higher the seam stress in warp direction.

\section{Seam efficiency in warp direction for fabric 2 (satin)}

$Y=0.4-0.04 *$ th $*$ st. $t+0.01 *$ st. $d^{2} \quad R^{2}=0.81$

Where Y: seam efficiency in warp direction for fabric 2 (satin)

From equation 4 It is obvious that the factors affecting seam efficiency in warp direction for fabric1 (satin fabric) are the same of the factors affecting seam stress in warp direction.

Seam strain in warp direction for fabric 2 (satin)

The following regression equation was obtained

$Y=17.7-3 *$ th $+0.69 *$ st. $d *$ st. $t \quad R^{2}=0.86$

Where Y: Seam strain in warp direction for fabric 2(satin).

From equation 5, It can be detected that sewing thread count has a major negative effect on the seam strain in warp direction for satin fabric which means the higher the yarn count in Tex (coarser yarn) the lower the seam strain in warp direction. Also the interaction between stitch density and stitch type affects seam strain in warp direction positively for satin fabric positively. Using of stitch type 301 (lock stitch) with less number of stitch density gives the lowest seam strain and stitch type 514 (overlock with 5 thread) with highest number of stitches per centimeter gives the highest seam strain. From the previous speech it can be said that using finer yarn count with stitch type 514 and the highest number of stitches per centimeter ( 7 stitches per centimeter) gives the highest seam strain in warp direction for satin fabric.

\section{Seam stress in weft direction for fabric 2 (satin) \\ The following regression model was obtained: $Y=0.116+0.0067 *$ st. $t^{2}-0.0369 *$ th $\quad R^{2}=0.66$}

Where Y: Seam stress in weft direction for fabric 2 (satin). From equation 6,It is obvious that the factors affecting the seam strength in warp direction are the square of stitch type and sewing thread count. It is obvious that the square of stitch type has positive effect on weft seam strength which means that stitch type 515 (overlock with five threads) gives higher seam strength in weft direction. Also it is clear that the thread count affects seam strength in weft direction negatively which means that the higher the count in tex (thicker yarn) the lower the weft seam strength, this could be as a result of fabric mechanical damage caused by thicker sewing thread. In other words the using stitch type 515 with thinner sewing thread give the highest seam stress in weft direction for satin fabric. Seam efficiency in weft direction for fabric 2 (satin)

The following regression model was obtained:

$Y=0.18+0.01 *$ st. $t^{2}-0.06 *$ th $\quad R^{2}=0.66$

Where Y: Seam efficiency in weft direction for fabric 2 (satin).

From equation7, it is obvious that the factors affecting seam efficiency in weft direction for fabric2 (satin fabric) are the same of the factors affecting seam stress in weft direction.

\section{CONCLUSION}

- Using thinner sewing thread count with stitch type 301 (lock stitch) gives the highest seam stress in warp direction for both fabrics under study, while coarse sewing with stitch type 515 (overlock with 5 thread) gives the lowest seam stress in warp direction.

- Stitch type affects seam stress in weft direction for satin fabrics positively, while it affects seam stress in warp direction negatively for both fabrics. In other words Stitch type 515 gives the highest seam stress in weft direction for satin fabric and stitch type 301 gives the lowest seam stress in weft direction for satin fabric. While Stitch type 301 gives the highest seam stress in warp direction for both fabrics and stitch type 515 gives the lowest seam stress in weft direction for both fabrics under study.

- Sewing thread count has negative effect on seam stress in both directions for both fabrics under study. The same effect was found for seam strain in warp direction for satin fabric. In other words The lower sewing thread count gives higher seam stress in both warp and weft direction for both fabrics under study.

- For satin fabric Using stitch type 515 with 7 stitches per centimeter gives the higher seam strain in warp direction. While using 301 with 5 stitches per centimeter gives the lowest seam strain in warp direction.

- The higher the number of stitches per centimeter the higher the seam stress in warp direction for both fabrics under study. 
- Stitch type affects seam stress in warp direction for both fabrics under study negatively, while it affects seam stress in weft direction for satin fabric positively. Stitch type 301 gives the higher seam stress in warp direction than stitch type 504 and 515 for both fabrics under study, while it gives the lower seam stress in weft direction for satin fabric. Also it gives lower seam strain in warp direction than other stitch types used for satin fabric.

\section{REFERENCES}

[1] Mandal S., Studies on Seam Quality with Sewing Thread Size, Stitch Density and Fabric Properties, Master thesis, The Hong Kong Polytechnic University, Institute of Textile \& Clothing, 2008.

[2] Shawky M., Effect of Home Laundering on Sewing Performance of Cotton Fabrics, Journal of Basic and Applied Scientific Research, Vol 3, No12, 2013,pp.457-463.

[3] Behera B. K., Chand S., Singh T.G. and Rathee P., Sewability of Denim, International Journal of Clothing Science and Technology, Vol. 9 No. 2, 1997, pp.128-140.

[4] Namiranian R., Najar S. S., Etrati S. M. and Manich A. M., Seam Slippage and Seam Strength behavior of Elastic Woven Fabrics under Static Loading, Indian Journal of Fibre \& Textile Research, Vol. 39, 2014, pp. 221-229.

[5] Ünal B. Z., The prediction of seam strength of denim fabrics with mathematical equations, The Journal of The Textile Institute, Vol. 103, No. 7, 2012, pp 744-751.

[6] Popov, Nenad Cirkovic, Jovan Stepanovic, The Influence of Stitch Density and of the Type of Sewing thread on Seam Strength, TEM Journal, Volume 1, No2, 2012, pp 104-110.

[7] Sauri R. M., Manich A. M., Barella A. and Lloria J., A Factorial Study of Seam Resistance; Woven and Knitted Fabrics, Indian Journal of Textile Research, Vol. 12, 1987, pp. 188-193.

[8] Choudhary A. K. and Goel A., Effect of Some Fabric and Sewing Conditions on Apparel Seam Characteristics, Journal of Textiles, Vol. 2013, Article ID 157034, 2013.

[9] Sülara V., Meşegülb C., Kefsizc H. and Sekia Y., A comparative study on seam performance of cotton and polyester woven fabrics, The Journal of The Textile Institute, Vol. 106, No. 1, 2015, pp.19-30.

[10] Yusof N. J. M., Suhaimi S. A. and Ruznan W. S., Suitability of Sewing Thread on Different Types of sheer Fabrics, Proceedings of the International Conference on Science, Technology and Social Sciences (ICSTSS), 2012.

[11] Krasteva D. G. and Petrov H., Investigation on the seam's quality by sewing of light fabrics, International Journal of Clothing Science and Technology, Vol. 20 Iss 1, 2008, pp. $57-64$.

[12] A.S.T.M. D 1683-04, "Standard Test Method for Failure in Sewn Seams of Woven Apparel Fabrics", 2004.

[13] ISO: 13935-1, Textiles -- Seam tensile properties of fabrics and made-up textile articles -- Part 1: "Determination of maximum force to seam rupture using the strip method", 2014 